\title{
Success rate and complications of endonasal dacryocystorhinostomy with unciformectomy
}

\author{
Jae Wook Yang $\cdot \mathrm{Ha} \mathrm{Na}$ Oh
}

Received: 8 October 2011 /Revised: 21 February 2012 / Accepted: 27 February 2012 / Published online: 24 May 2012

(C) Springer-Verlag 2012

\begin{abstract}
Background Endonasal dacryocystorhinostomy (DCR) has been widely used to treat nasolacrimal duct obstruction. Here, we evaluated the anatomical advantages of the uncinate process as a landmark and to study the effect of unciformectomy on success rate and complications of endonasal DCR .

Methods In total, 288 eyes of 265 adult patients who underwent endonasal DCR between January 2003 and February 2010 were reviewed retrospectively. The eyes were classified into two groups, according to whether unciformectomy was performed or not. All surgical procedures and surgical indications were the same except unciformectomy and endonasal DCR was performed by one surgeon. Unciformectomy was performed by resecting the anterior part of uncinate process. Results One hundred and eighty-six eyes of 168 patients received endonasal DCR with unciformectomy, and 102 eyes of 97 patients received endonasal DCR alone. The average success rate of endonasal DCR with unciformectomy was
\end{abstract}

There was no financial relationship in our study, and we have no conflict of interest.

It has never been presented at any other conference.

All authors have full control of all primary data, and agree to allow Graefe's Archive for Clinical and Experimental Ophthalmology to review our data.

This work was supported by the 2012 Inje University research grant.

J. W. Yang $(\bowtie) \cdot H$. N. Oh

Department of Ophthalmology, Busan Paik Hospital, Inje University Medical College,

Gaegum-dong, Busanjin-gu,

Busan 633-165, Korea

e-mail: eyeyang@inje.ac.kr

J. W. Yang $\cdot$ H. N. Oh

Inje University College of Medicine, Busan Paik Hospital,

Ophthalmology Research Foundation,

Busan, Korea
$97.8 \%$ and that of endonasal DCR alone was $90.2 \%$, with statistically significant difference (Student's $t$-test, $p$-value $<$ 0.05 ). There were 14 eyes with post-operative nasolacrimal obstruction, caused by granuloma in five eyes, intranasal synechia in two eyes, membranous obstruction in six eyes, and canalicular stenosis in one eye. There were no serious complications such as orbital fat prolapse, cerebrospinal fluid leak, or delayed hemorrhage.

Conclusions Anterior resection of the uncinate process gives improved access to the lacrimal bone by exposing the medial aspect of the lacrimal fossa and forming the precise location of the osteotomy on the lacrimal bone during endonasal DCR. Thus, the uncinate process can be used as an anatomical landmark for endonasal DCR. The unciformian endonasal DCR improves operation success rate by allowing access to the large space of the nasal cavity and reducing the synechiae of the nasal cavity.

Keywords Endonasal dacryocystorhinostomy .

Nasolacrimal duct obstruction $\cdot$ Postoperative

complications $\cdot$ Success rate $\cdot$ Uncinate process

\section{Introduction}

DCR is commonly used to treat nasolacrimal duct obstruction. It is a surgical method of making an ostium at the lacrimal bone to form a shunt in the nasolacrimal pathway. During most of the previous century, external DCR was standard treatment for nasolacrimal duct obstruction because of its intraoperative approach to the lacrimal sac and the high success rate, whereas intranasal DCR has technical difficulties visualizing the surgical site and achieving effective soft-tissue and bone removal [1, 2]. However, since the development of the rigid fiberoptic endoscope, endonasal DCR has been 
widely used because it has significant advantages, including the avoidance of scarring, minimal postoperative hematoma, shorter postoperative recovery, preservation of the pumping action on the orbicularis oculi muscle, and concurrent correction of intranasal abnormalities, which can cause failure from synechiae formation between the ostium and the septum or the middle turbinate using the endoscope [3-6].

Despite these advantages, endonasal DCR has a number of factors that can lead to failure. Anatomical variation in the nasal cavity can cause difficulties for surgical correction. Insufficient size of the osteotomy [6], cicatricial closure of the ostium [7-9], adhesions between the ostium and the middle turbinate [10], formation of synechiae between the ostium and the nasal septum [7], and granuloma formation within the ostium [7] can cause postoperative nasolacrimal duct obstruction. Thus, resolving these factors and overcoming anatomical variations will improve the success rate of endonasal DCR.

The uncinate process is a thin bony layer that extends from the anterior end of the middle meatus, and spreads downwards and backwards above the upper aspect of the maxillary sinus [5]. The anterior part of the uncinate process faces the lacrimal bone. McDonogh and Meiring [11] suggested the potential use of the uncinate process as a landmark in endonasal dacryocystorhinostomy.

In our research we have experienced favorable results and prognosis in the treatment of patients with nasolacrimal duct obstruction, using endonasal DCR with unciformectomy. Here, we evaluated the anatomical advantages of the uncinate process as a landmark, and studied the effect of unciformectomy on the success rate and complications of endonasal DCR. We suggest other contributing factors that may improve the success rate in comparison with our previous study.

\section{Materials and methods}

In total, 265 adult patients with symptomatic nasolacrimal duct obstruction underwent endonasal DCR between January 2003 and February 2010. Patients were followed for longer than 6 months. In total, 288 eyes were included in the study; both eyes in 23 patients and a single eye in 242 patients. The eyes were classified into two groups according to whether unciformectomy was performed or not (group A : endonasal DCR with unciformectomy, group B : endonasal DCR alone). The success rate and complications of the both groups were studied.

Nasolacrimal duct obstruction was confirmed prior to the operation by positive probing (bone contact) and negative irrigation. Dacryocystography was performed in some cases, by injection of contrast (Ultravist injection ${ }^{\circledR} 370$, Bayer, Germany) into the lacrimal canaliculi and lacrimal sac to show the blocked or constricted location of nasolacrimal pathway. Nasal cavity abnormalities were not considered in assessing the result of our endonasal DCR with unciformectomy.

All surgical procedures and surgical indications were the same except unciformectomy and endonasal DCR was performed by one surgeon. Patients underwent general anesthesia, and gauze soaked with $1 \%$ lidocaine and 1:1000 epinephrine mixed solution was packed into the nasal cavity to decongest the nasal mucosa after anesthesia. The upper and lower punctum were dilated. The 20-gauge vitrectomy light source tip was inserted into the lower punctum and reached the lacrimal sac. After identifying the location of the lacrimal sac by transillumination, local anesthetic was injected into the nasal mucosa of the transilluminated areas around the uncinate process. In some patients, procedures including middle turbinectomy, fracturing techniques of septal cartilage by pushing the septum and the removal of nasal polyps were performed to enlarge the nasal cavity. The mucosa on the anterior part of the uncinate process was removed via the anterior, through the insertion of the middle turbinate using a Freer elevator. The lacrimal bone was exposed after resection of the anterior of the uncinate process. Nasal mucosa and lacrimal bone were removed, and the ostium was increased in size to $>8 \mathrm{~mm}$ diameter by extensive removal of bony fragments. The lacrimal sac was opened with a keratome knife to at least $5 \mathrm{~mm}$ diameter. Ostium patency was confirmed by irrigation through the lower punctum. The incised lacrimal sac mucosa was continuous with the nasal mucosa. Bicanalicular silicone intubation was performed, where the two ends of the silicone tube were tightened together inside the nose. Finally, antiadhesive agent comprised of sodium hyaluronate and sodium carboxymethyl cellulose (Guardix-sol ${ }^{\circledR}$, Biorane, Korea) soaked gauze was packed at the site of the operation.

Patients were routinely released from hospital on the third postoperative day. They were taught to wash the nasal cavity, removing blood clots and postoperative debris. An antibiotic eye solution, weak steroid eye solution, and nasal spray were used for nasal care during the first week after the operation. The silicone tube was removed after 3 months. Postoperative assessments at 1 week, 1 month, 3 months (silicone tube removal), 6 months, and 12 months were conducted, including analysis of symptoms, such as pain, epiphora, and posterior rhinorrhea.

Intraoperative complications such as orbital fat prolapse, retrobulbar hemorrhage, cerebrospinal fluid leakage and postoperative complications including delayed hemorrhage (epistaxis), medial rectus palsy, progressive closure of the ostium, development of adhesions between the ostium and the nasal septum, granuloma formation within the ostium, orbital/subcutaneous emphysema, hematoma, synechia, canalicular stenosis, and conjunctival fistula were investigated from the inspection and endoscopic examination. Operations were considered successful if there was symptom relief, and patent 
ostium on nasal endoscopy and irrigation. Failure was defined as absence of symptom relief, closed ostium on endoscopy and not patent on irrigation.

\section{Results}

Patients were aged between 16 and 84 years old (mean: 47.1 \pm 12.1 years). In total, 288 eyes of 265 patients (males $(n=$ $59)$ and females $(n=211))$ were included in the study, both eyes in 23 patients and a single eye in 242 patients. The mean observation period was $10.8 \pm 1.8$ months (range, 639 months).

One hundred and eighty-six eyes of 168 patients received endonasal DCR with unciformectomy, and 102 eyes of 97 patients received endonasal DCR alone. There was no significant difference in preoperative factors such as patients' demographics or site of obstruction between two groups. The average success rate of group A (endonasal DCR with unciformectomy) was $97.8 \%(182 / 186)$, and that of group B (endonasal DCR alone) was $90.2 \%(92 / 102)$, with a statistically significant difference (Student's $t$-test, $p$-value $=$ 0.016). The clinical study showed a favorable success rate of endonasal DCR with unciformectomy surgical procedure compared with endonasal DCR alone for nasolacrimal obstruction.

In total, 182 eyes of group A and 92 eyes of group B had a patent nasolacrimal duct, based on irrigation and endonasal endoscopy; 168 eyes of group A and 84 eyes of group $\mathrm{B}$ were free of clinical symptoms (tearing) during the follow-up period; 14 eyes of group A and eight eyes of group $\mathrm{B}$ reported intermittent tearing from exposure to wind or cold. Four eyes of group A and ten eyes of group B had recurrent epiphora and required reoperation. Postoperative nasolacrimal duct obstruction of group A was caused by granuloma in two, intranasal synechia in one, and membranous obstruction in one eye (Fig. 1). There were ten complications of group B, including membranous obstruction in five, granuloma in three, intranasal synechia in one, and canalicular stenosis in one eye. There was no case of mucosal burn, orbital fat prolapse, cerebrospinal fluid leak, maxillary sinusitis, or delayed bleeding.

\section{Discussion}

DCR is widely used to treat nasolacrimal duct obstruction. It can be performed via the skin (external DCR) or intranasally (endonasal DCR). External DCR has usually been performed because of the accessible location of the lacrimal sac and its high success rate, approximately 90-96\%.

However, external DCR has several potential complications, including postoperative hemorrhage, skin scarring,
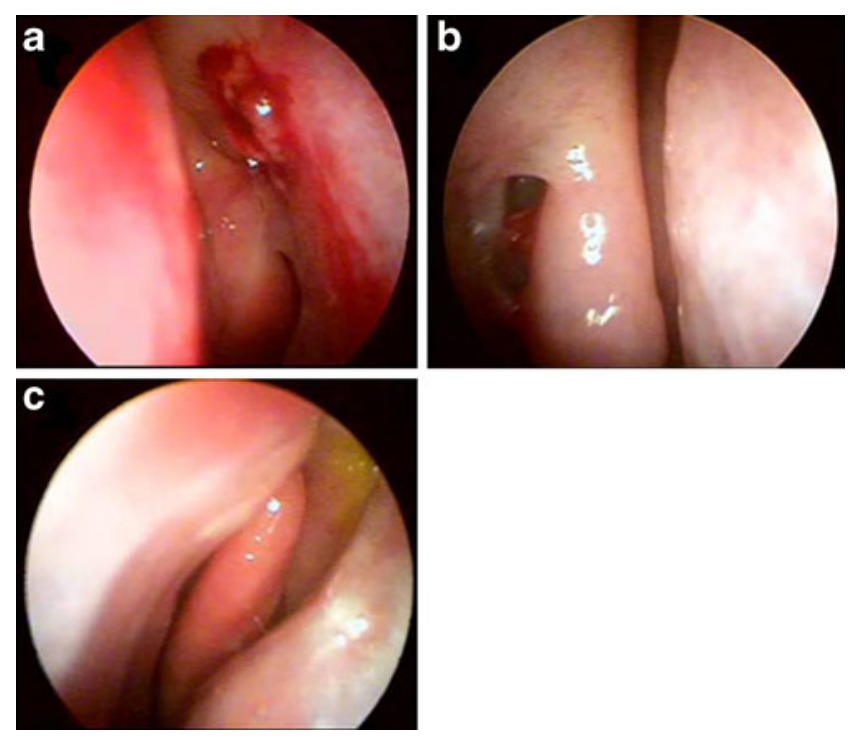

Fig. 1 The causes of nasolacrimal duct re-obstruction. a Granuloma. b Intranasal synechia. c Membranous obstruction

and slow recovery time $[12,13]$. The external approach may be associated with unrecognized trauma to the anterior ethmoid, middle turbinate, and nasal septum, without preventing further complications such as synechiae due to the absence of a clear visual assessment of the nasal cavity. Further, less frequent complications have been reported, including cutaneous necrosis, cerebrospinal fluid leakage, maxillary and frontal sinusitis, retrobulbar hemorrhage, transient lagophthalmos, and subcutaneous emphysema [14-16].

The deliberate management of endonasal structures required to gain access to the surgical site of the osteotomy prevents mucosal synechiae that eventually causes difficulties or failure of the endonasal DCR.

However, endonasal DCR has significant advantages over external DCR, including avoidance of scarring, minimal postoperative hematoma, shorter postoperative recovery time, preservation of the pumping action on the orbicularis oculi muscle, and the ability to concurrently correct intranasal abnormalities, which can cause failure from synechiae formation between the ostium and the septum or the middle turbinate using the endoscope [3-6].

Success of endonasal DCR is affected by a number of factors. Variations of the size of the nasal cavity (Fig. 2), insufficient size of the osteotomy [6], cicatricial closure of the ostium [7-9], adhesions between the ostium and the middle turbinate [10], formation of synechiae between the ostium and the nasal septum [7], granuloma formation within the ostium [7], and intracanalicular obstruction can all lead to a decrease in the success rate of endonasal DCR.

There is a lack of standardization of the endonasal DCR procedure due to anatomical variability. The critical step of DCR is the osteotomy, where adequate size and location 

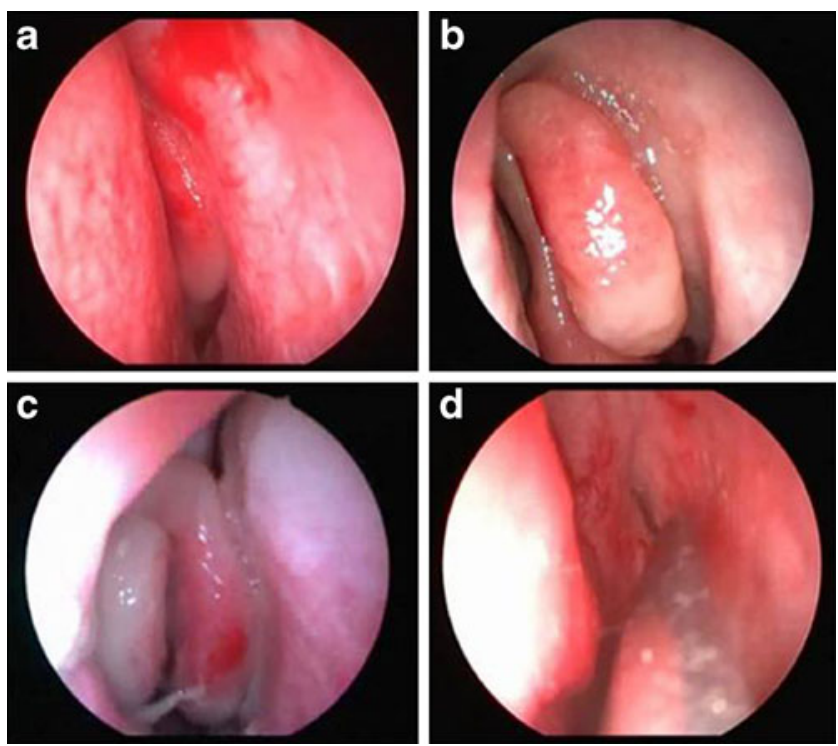

Fig. 2 Anatomical variations in nasal cavity found during our endonasal dacryocystorhinostomy procedure. a Septal deviation. b Medial rotation of middle turbinate. c Nasal polyp. d Narrow nasal cavity due to nasal mucosa swelling

allows the anastomosis of the lacrimal and nasal mucosa, an important condition for the long-term patency of the nasolacrimal shunt [6]. Thus, reliable markers, independent of the anatomical variations, are clinically important to the success of endonasal DCR

According to an anatomical relationship between the frontal process of the upper maxillary, lacrimal bone and the uncinate process, the uncinate process was reported to be a reliable landmark for the lacrimal fossa [17]. The anterior section of the uncinate process is consistently close to the lacrimal bone [18, 19]. Yung and Hardman-Lea [20] reported that cleavage of the suture between the maxillary bone and the uncinate process exposed the lacrimal bone and the lacrimal sac.

Several reports [21-27] recommend initiating osteotomy at the nasal ridge anterior to the uncinate process in the frontal process of maxilla. The required drilling for this procedure may be difficult to initiate and continue into the thick maxillary bone to the distant common canaliculus, and this uncontrolled approach increases the risk of misdirected drilling or laser delivery leading to adverse effects, including orbital fat prolapse, hematoma, emphysema, mucosal burn [27], damage of the inferior oblique muscle [27], sectioning of the anterior ethmoidal artery [27], or sectioning of the optic nerve.

Regardless of the level at which it is attached to the maxillary bone or to the lacrimal bone, the uncinate process can be readily identified by its texture and size, and is easily detached and pushed medially to perform an anterior unciformectomy (Fig. 3). Thus, the uncinate process can serve as a landmark for standardization of endonasal DCR ,because

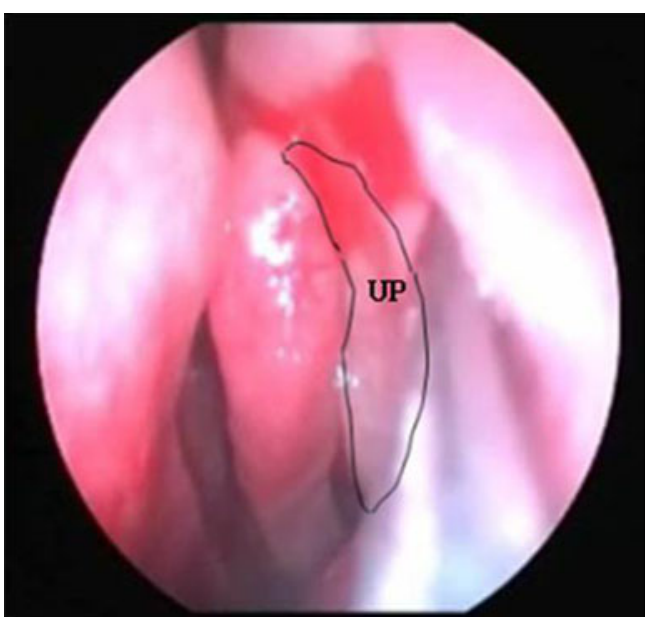

Fig. 3 Uncinate process (UP) : UP is attached to the maxillary bone or to the lacrimal bone. The UP can be readily identified by its texture and size

it can give adequate size and the location of the osteotomy [6]. Soyka analyzed the radiological anatomy of the uncinate process as an access to the lacrimal sac [28], and we analyzed the uncinate process and easily found it with endoscopy. In conventional endonasal DCR, osteotomy is usually initiated at the lacrimal ridge $[22,29,30]$ and then enlarged forward into the nasal fossa until the lacrimal sac is exposed. Planned unciformectomy has been reported to help overcome the variability of endonasal anatomical structures $[5,11]$ by providing direct, safe access to the lacrimal fossa. In the present study, the nasal cavity was enlarged by anterior resection of uncinate process (Fig. 4). This allowed the easy operation of the surgical instruments, and the creation of an ostium at the correct location, reducing postoperative adhesions or synechiae in the nasal cavity, enhancing the success rate, and reducing complications.

Our study confirmed that cleavage of the uncinate process provides more direct access to the lacrimal fossa, through the anterior of the ethmoid [5]. Performing a
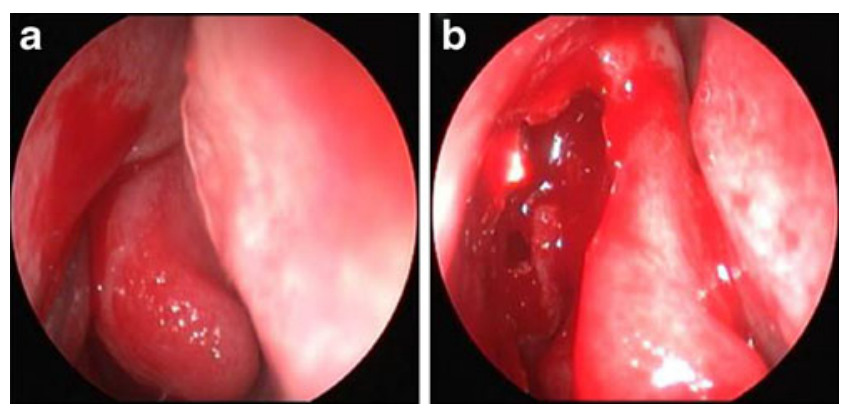

Fig. 4 a Middle turbinate (MT) hypertrophy and paradoxical rotation : the nasal cavity space was narrow because of MT hypertrophy and paradoxical rotation. b Post resection of the UP : the nasal cavity space was enlarged. The unciformectomy permitted a endonasal dacryocystorhinostomy surgical procedure in wide surgical vision, and decreased postoperative adhesion or synechiae 
standard endonasal DCR with anterior resection of the uncinate process, we experienced a high success rate of $97.8 \%$ $(182 / 186)$ for patients with nasolacrimal obstruction There was also no serious complication.

Thus, our results suggest that it is safe to expose the lacrimal sac by cleaving the uncinate process from its lateral attachment to the medial aspect of the lacrimal fossa with unciformectomy, increasing the success rate compared with endonasal DCR without unciformectomy.

We also suggest that the increased success rate is due to our surgical techniques. First, we extensively removed bony fragments around the ostium and used guardix packing in all cases. Second, we corrected abnormalities of the nasal cavity by turbinectomy using nasal endoscopy, and formed continuity between the lacrimal and nasal mucosa. Third, we incised the opening flap of lacrimal sac more than $5 \mathrm{~mm}$. But longer follow-up is needed to conclude conclusively the long-term success rates with this procedure.

Acknowledgements The authors are grateful to Inje university College of Medicine, Busan paik hospital, ophthalmology research foundation for their study assistance. All authors participated in the development and writing of this manuscript and are fully responsible for this study.

\section{References}

1. Hartikainen J, Antila J, Varpula M, Puukka P, Seppä H, Grénman $\mathrm{R}$ (1998) Prospective randomised comparison of endonasal endoscopic dacryocystorhionstomy and external dacryocystorhinostomy. Laryngoscope 108:1861-1866

2. Yoon SW, Yoon YS, Lee SH (2001) Clinical results of endoscopic dacryocystorhinostomy using a microdebrider. Ophthalmology 108:2369-2377

3. Watkins LM, Janfaza P, Rubin PA (2003) The evolution of endonasal dacryocystorhinostomy. Surv Ophthalmol 48:73-84

4. Rice DH (1990) Endoscopic intranasal dacryocystorhinostomy results in four patients. Arch Otolaryngol Head Neck Surg 116:1061

5. Fayet B, Racy E, Assouline M (2002) Systematic unciformectomy for a standardized endonasal dacryocystorhinostomy. Ophthalmology 109:530-536

6. Fayet B, Racy E, Assouline M (2004) Complications of standardized endonasal dacryocystorhinostomy with unciformectomy. Ophthalmology 111:837-845

7. Boush GA, Lemke BN, Dortzbach RK (1994) Results of endonasal laser-assisted dacryocystorhinostomy. Ophthalmology 101:955-959

8. Camara JG, Bengzon AU, Henson RD (2000) The safety and efficacy of mitomycin $\mathrm{C}$ in endonasal endoscopic laser-assisted dacryocystorhinostomy. Ophthal Plast Reconstr Surg 16:114-118
9. Woog JJ, Metson R, Puliafito CA (1993) Holmium:YAG endonasal laser dacryocystorhinostomy. Am J Ophthalmol 116:1-10

10. Hausler R, Caversaccio M (1998) Microsurgical endonasal dacryocystorhinostomy with long-term insertion of bicanalicular silicone tubes. Arch Otolaryngol Head Neck Surg 124:188-191

11. McDonogh M, Meiring JH (1989) Endoscopic transnasal dacryocystorhinostomy. J Laryngol Otol 103:585-587

12. Tarbet KJ, Custer PL (1995) External dacryocystorhinostomy. Surgical success, patient satisfaction, and economic cost. Ophthalmology 102:1065-1070

13. Jordan DR (1991) Avoiding blood loss in outpatient dacryocystorhinostomy. Ophthal Plast Reconstr Surg 7:261-266

14. Neuhaus RW, Baylis HI (1983) Cerebrospinal fluid leakage after dacryocystorhinostomy. Ophthalmology 90:1091-1095

15. Wesley RE, Bond JB (1986) Intranasal procedures for successful lacrimal surgery. Ophthal Plast Reconstr Surg 2:153-157

16. Hurwitz JJ, Eplett CJ, Fliss D, Freeman JL (1992) Orbital hemorrhage during dacryocystorhinostomy. Can J Ophthalmol 27:139-142

17. Yung MW, Logan BM (1999) The anatomy of the lacrimal bone at the lateral wall of the nose: its significance to the lacrimal surgeon. Clin Otolaryngol 24:262-265

18. Yoon JH, Kim KS, Jung DH, Kim SS, Koh KS, Oh CS, Kim HJ, Lee JG, Chung IH (2000) Fontanelle and uncinate process in the lateral wall of the human nasal cavity. Laryngoscope 110:281-285

19. Wormald PJ, McDonogh M (1998) The "swing-door"technique for uncinectomy in endoscopic sinus surgery. $\mathrm{J}$ Laryngol Otol 112:547-551

20. Yung MW, Hardman-Lea S (1998) Endoscopic inferior dacryocystorhinostomy. Clin Otolaryngol 23:152-157

21. Steadman MG (1985) Transnasal dacryocystorhinostomy. Otolaryngol Clin North Am 18:107-111

22. Weidenbecher M, Hosemann W, Buhr W (1994) Endoscopic endonasal dacryocystorhinostomy: results in 56 patients. Ann Otol Rhinol Laryngol 103:363-367

23. Menerath JM, Guichard C, Kydavongs P (1999) Endonasal dacryocystorhinostomy using endoscopic guidance. Personal experience. J Fr Ophtalmol 22:41-45

24. Gutiérrez-Ortega AR, Sprekelsen-Gasso C, Valles-San Leandro L, Delmperial JM (1995) Endonasal dacryocystorhinostomy:first results. Orbit 14:25-28

25. Friedrich JP, Tritten JJ (1998) Dacryocystorhinostomy by nasal endoscopy. an example of multidisciplinary collaboration. Rev Med Suisse Romande 118:235-239

26. El Khoury J, Rouvier P (1992) Endonasal dacryocystorhinostomy. Acta Otorhinolaryngol Belg 46:401-404

27. Bernal Sprekelsen M, Barberán M (1996) Endoscopic dacryocystorhinostomy: surgical technique and results. Laryngoscope 106:187-189

28. Soyka MB, Treumann T, Schlegel CT (2010) The agger nasi cell and uncinate process, the keys to proper access to the nasolacrimal drainage system. Rhinology 48:364-367

29. Cokkeser Y, Evereklioglu C, Er H (2000) Comparative external versus endoscopic dacryocystorhinostomy: results in 115 patients (130 eyes). Otolaryngol Head Neck Surg 123:488-491

30. Javate RM, Campomanes BS Jr, Co ND, Dinglasan JL Jr, Go CG, Tan EN, Tan FE (1995) The endoscope and the radiofrequency unit in DCR surgery. Ophthal Plast Reconstr Surg 11:54-58 